\title{
Discrimination of Oribotritia species by oil gland chemistry (Acari, Oribatida)
}

\author{
Günther Raspotnig • Verena Leutgeb • Günther Krisper • \\ Hans-Jörg Leis
}

Received: 6 January 2011/Accepted: 10 February 2011/Published online: 25 February 2011

(C) The Author(s) 2011. This article is published with open access at Springerlink.com

\begin{abstract}
The chemical composition of secretions from opisthonotal (oil) glands in four species of the oribatid mite genus Oribotritia (Mixonomata, Euphthiracaroidea, Oribotritiidae) was compared by means of gas chromatography-mass spectrometry. The secretions of all, $O$. banksi (from North America) and three Austrian oribotritiids $(O$. berlesei, $O$. hermanni, O. storkani), are shown to be based on certain unusual compounds, the iridoid monoterpenes chrysomelidial and epi-chrysomelidial and the diterpene $\beta$-springene. These components probably represent general chemical characteristics of oribotriid oil glands. Their relative abundance in the secretions along with further components (mainly saturated and unsaturated $\mathrm{C}_{13^{-}}, \mathrm{C}_{15^{-}}, \mathrm{C}_{17^{-}}$-hydrocarbons, and the tentatively identified octadecadienal) led to well-distinguishable, species-specific oil gland secretions profiles. In addition a reduced set of "Astigmata compounds" (sensu Sakata and Norton in Int J Acarol 27:281-291, 2001)—namely the two monoterpenes neral and geranial—could be detected in extracts of $O$. banksi nevertheless indicating the classification of euphthiracaroids within the (monophyletic) group of "Astigmata compounds-bearing"-Oribatida. These compounds are considered to be apomorphically reduced in all Austrian species. Our findings emphasize the potential of chemosystematics using oil gland secretion profiles in the discrimination of morphologically very similar, syntopically living or even cryptic oribatid species.
\end{abstract}

Keywords Opisthonotal glands · Astigmata compounds · Chrysomelidial · Epi-chrysomelidial · Chemical ecology

G. Raspotnig $(\bowtie) \cdot$ V. Leutgeb · G. Krisper

Institute of Zoology, Karl-Franzens-University, Universitätsplatz 2, $8010 \mathrm{Graz}$, Austria

e-mail: guenther.raspotnig@uni-graz.at

G. Raspotnig · H.-J. Leis

Childrens Hospital, Research Unit of Osteology and Analytical Mass Spectrometry,

Medical University, Auenbruggerplatz 30, 8036 Graz, Austria 


\section{Introduction}

The majority of the 10,000 species of oribatid mites (Acari, Oribatida) possesses a characteristic paired, opisthonotal ("oil") gland system that is known to produce a variety of exocrine compounds: A series of terpenes, aromatics, and hydrocarbons has been identified from oil glands of early- and middle-derivative glandulate oribatids (Parhyposomata, Mixonomata and Desmonomata) and from juvenile stages in some Brachypylina (Sakata and Norton 2001; Raspotnig et al. 2001; Takada et al. 2005). In addition, various toxic alkaloids have been detected in extracts of certain adult brachypyline Oribatida, and the oil gland-origin of these compounds is likely as well, though just conjecture at this time (e.g., Saporito et al. 2007; Raspotnig et al. 2011). By using modern gas chromatographic-mass spectrometric methods, chemical profiles of oil gland secretions can meanwhile be evaluated from individual mite specimens, clearly indicating that oil gland derived-compounds are arranged in stable, group- or even species-specific combinations (e.g., Raspotnig 2010; Raspotnig and Föttinger 2008). Such profiles have emerged as a pool of novel characters for taxonomic and phylogenetic investigations (e.g., Raspotnig 2006a; Weigmann and Raspotnig 2009), and are useful to characterise oribatid groups on different taxonomic levels. One major chemically-definable and probably monophyletic group is the "Astigmata compoundsbearing" Oribatida. This group is regarded to include all Oribatida above middle-derivative mixonomatans (including the astigmatid mites) and is characterised by so-called "Astigmata compounds" (sensu Norton and Sakata 2001). "Astigmata compounds" are a set of terpenes (neral, geranial, neryl formate) and aromatics (2-hydroxy-6-methyl-benzaldehyde, $\gamma$-acaridial) which are thought to have evolved only once within ancestors of certain Mixonomata, and are considered to be spread all over its descendants. However, in certain sub-groups of the "Astigmata compounds-bearing" Oribatida, these components are not easy to trace due to various degrees of reductions (e.g., Raspotnig et al. 2009) or even replacements by other components. One of these problematic taxa is the Euphthiracaroidea, a major mixonomatan group that - together with the Phthiracaroidea-constitutes the so-called box mites or Ptyctima (e.g., Grandjean 1954, 1969). While in phthiracaroids oil glands appear to be entirely lost, oil glands in euphthiracaroids are prominent and well developed.

The first example of euphthiracaroid oil gland chemistry has recently been published (Raspotnig et al. 2008), picturing a surprisingly aberrant composition of oil gland secretions, at least in the model euphthiracarid species Oribotritia berlese $i$ : Instead of the expected Astigmata compounds, unusual iridoid monoterpenes (chrysomelidials) and a diterpene ( $\beta$-springene) were found, representing exocrine compounds so far unique amongst Oribatida. In the present study, we used four species of Oribotritia (one species from North America, O. banksi, and three species from Austria, O. berlesei, O. hermanni, and $O$. storkani) for an extended and comparative investigation into oribotritiid oil gland chemistry. The study focuses on three main aims: (1) to verify the unusual, iridoid monoterpene-rich oil gland chemistry of $O$. berlesei (as recently reported by Raspotnig et al. 2008) as a common phenomenon in Oribotritiidae or at least for genus Oribotritia; (2) to investigate whether oil gland secretion profiles constitute discriminant characters even between closely related species of one and the same genus; and (3) to clarify the situation of the occurrence of "Astigmata compounds" in the Euphthiracaroidea. 


\section{Materials and methods}

Mites and mite extracts

Specimens of Oribotritia berlesei (Michael), O. hermanni (Grandjean), and O. storkani (Feider and Suciu) ("mixonomatan" Oribatida: Euphthiracaroidea, Oribotritiidae) were collected from the litter and fermentation layer of mixed forests at several sites in Austria (Table 1). In some cases, syntopic occurrence of two of the species was recorded, especially for $O$. berlesei/O. hermanni (collection site 2) and for O. hermannilO. storkani (collection site 5). Oribotritia banksi (Oudemans) was extracted from two soil samples from West Virginia both of which were kindly provided by Roy A. Norton (SUNY ESF, Syracuse, New York).

Adult specimens of both sexes, in detail 20 specimens of $O$. berlesei, 16 specimens of $O$. hermanni, five specimens of $O$. storkani, and seven specimens of $O$. banksi were used in this study. Individual extracts containing oil gland secretions were prepared by submersion of freshly collected, living specimens in hexane (one individual per $100 \mu \mathrm{l}$ ) for a maximum of $30 \mathrm{~min}$. This method leads to the access of oil gland secretion components; secretions

Table 1 Collection of Oribotritia-species

\begin{tabular}{|c|c|c|c|c|c|}
\hline & $\begin{array}{l}\text { Collection } \\
\text { no. }\end{array}$ & Location & Date & $\begin{array}{l}\text { Individuals } \\
\text { (no) }\end{array}$ & Extract no. ${ }^{b}$ \\
\hline \multirow[t]{6}{*}{$\begin{array}{l}\text { Oribotritia } \\
\text { berlesei }\end{array}$} & 1 & $\begin{array}{l}\text { Waidischbach near } \\
\text { Ferlach (Carinthia, } \\
\text { Austria) }\end{array}$ & 15 Sept 2002 & 6 & $\begin{array}{l}83,86,95,96 \\
\quad 97,98\end{array}$ \\
\hline & 2 & $\begin{array}{l}\text { Osce near Ferlach } \\
\text { (Carinthia, Austria) }\end{array}$ & 15 Sept 2002 & 3 & $87,88,89$ \\
\hline & 3 & $\begin{array}{l}\text { Maria Rain (Carinthia, } \\
\text { Austria) }\end{array}$ & 27 Oct 2002 & 1 & 117 \\
\hline & 4 & $\begin{array}{l}\text { Maria Rain (Carinthia, } \\
\text { Austria) }\end{array}$ & 5 April 2003 & 4 & $\begin{array}{l}198,199,201, \\
203\end{array}$ \\
\hline & 5 & Rauth (Carinthia, Austria) & 1 June 2003 & 5 & $\begin{array}{l}234,235,236 \\
237,239\end{array}$ \\
\hline & 6 & $\begin{array}{l}\text { Eichberg near Leutschach } \\
\quad \text { (Styria, Austria) }\end{array}$ & 25 March 2003 & 1 & 188 \\
\hline \multirow[t]{3}{*}{$\begin{array}{l}\text { Oribotritia } \\
\text { hermanni }\end{array}$} & 7 & $\begin{array}{l}\text { Maria Rain (Carinthia, } \\
\text { Austria) }\end{array}$ & 24 Nov 2002 & 1 & 128 \\
\hline & 8 & $\begin{array}{l}\text { Weizklamm (Styria, } \\
\text { Austria) }\end{array}$ & 28 April 2003 & 6 & $\begin{array}{l}210,212,215 \\
216,219,222\end{array}$ \\
\hline & 6 & $\begin{array}{l}\text { Eichberg near Leutschach } \\
\quad \text { (Styria, Austria) }\end{array}$ & 25 March 2003 & 9 & $\begin{array}{c}181,182,186, \\
187,190,193, \\
194,196,197\end{array}$ \\
\hline $\begin{array}{l}\text { Oribotritia } \\
\text { storkani }\end{array}$ & 8 & $\begin{array}{l}\text { Weizklamm (Styria, } \\
\text { Austria) }\end{array}$ & 28 April 2003 & 5 & $\begin{array}{l}206,207,211 \\
213,218\end{array}$ \\
\hline \multirow[t]{2}{*}{$\begin{array}{l}\text { Oribotritia } \\
\text { banksi }\end{array}$} & 9 & West Virginia (USA) & $2004^{\mathrm{a}}$ [collection 1] & 4 & $\begin{array}{l}489,501,552 \\
557\end{array}$ \\
\hline & 10 & West Virginia (USA) & $2004^{\mathrm{a}}$ [collection 2] & 3 & $1194,1334,1344$ \\
\hline
\end{tabular}

\footnotetext{
${ }^{a}$ Exact date of collection not available

b Extract numbers refer to internal labelling of individual extracts (these numbers are also used in the cluster analyses of Fig. 2.)
} 
are directly discharged into the solvent (for details see e.g., Raspotnig et al. 2001, 2004, 2005a, b). Crude hexane extracts were used for chemical analysis. Since extraction of oil gland contents in hexane is a non-destructive method, determination of mites on the species level was done after extraction. Determination of species was based on descriptions by Grandjean (1933, 1934, 1967), Feider and Suciu (1957), Forsslund and Märkel (1963), Märkel (1964), and Niedbala (2002).

Chemical analysis: gas chromatography—mass spectrometry

The analytical instruments for this study included a Trace gas chromatograph (GC) coupled to a Voyager mass spectrometer (MS) (both from Thermo, Vienna, Austria). The GC-column (a ZB-5MS fused silica capillary column: $30 \mathrm{~m} \times 0.25 \mathrm{~mm}$ i.d., $0.25 \mu \mathrm{m}$ film thickness from Phenomenex, Germany) was directly connected to the ion source of the MS. The splitless Grob injector was kept at $260^{\circ} \mathrm{C}$, and helium (at a constant flow rate of $1.5 \mathrm{ml} / \mathrm{min}$ ) was used as a carrier gas. All data in the text refer to the following temperature program: initial temperature $50^{\circ} \mathrm{C}$ for $1 \mathrm{~min}$, followed by an increase of $10^{\circ} / \mathrm{min}$ to $200^{\circ} \mathrm{C}$, with $15^{\circ} / \mathrm{min}$ to $300^{\circ} \mathrm{C}$, and an isothermal hold for $5 \mathrm{~min}$. The ion source of the mass spectrometer and the transfer line were kept at 150 and $310^{\circ} \mathrm{C}$, respectively. Electron ionisation (EI) spectra were recorded at $70 \mathrm{eV}$.

Derivatisation, syntheses, reference compounds and other chemicals

Tri-, penta-, and heptadecane as well as citral (60\% geranial, 40\% neral) and selene dioxide for the preparation of oxocitral (Bellesia et al. 1986) were purchased from Aldrich (Vienna, Austria). For determination of double bonds in the heptadecadiene, dimethyl-disulfide (DMDS) adducts were generated according to a method described by Vincenti et al. (1987). Stereoisomers of chrysomelidial and dehydroiridodial, respectively, were synthesized according to Bellesia et al. (1986). As natural sources for chrysomelidials, we used secretions from eversible defense glands of larvae of the chrysomelid beetles, Gastrophysa viridula and Plagiodera versicolora (collected in the surroundings of Graz, Austria) both of which are known to contain natural (3S,8S)-chrysomelidial (e.g., Pasteels et al. 1982, 1984, 1988). Secretions were sampled on small filter paper pieces, extracted in hexane (secretion of one individual in $100 \mu \mathrm{l}$ ), and used as references for chromatography. We further refer to our recent study on Oribotritia berlesei where chrysomelidial and epichrysomelidial were mass spectrometrically characterised in detail (Raspotnig et al. 2008).

Evaluation of secretion profiles and statistics

Secretion profiles were evaluated by integration of peak areas (of each of the 12 components in the chromatograms) and by calculation of the relative abundance of peaks, then expressed in $\%$ of peak area of whole secretion. The resulting profiles were subjected to different classification methods of multivariate statistics: (1) In order to determine the existence of distinct chemical groups, cluster analyses were performed (using PAST PAlaeontological STatistics, version 2.05). (2) Subsequently, stepwise discriminant analysis (using PASW for Windows, Version 18.0) was conducted to determine whether and how the previously (morphologically) determined individuals (=of four species) could be classed with the distinct chemical groups detected. All compounds of the extracts and their relative abundance, respectively, were treated as variables and all 48 cases 
(=corresponding to the 48 individual profiles determined) were used for the analyses. The estimation of the validity of the discriminant function was based on the significance of Wilk's Lambda and the percentage of correct assignment to a certain (morphologically defined) species.

\section{Results}

\section{Identification of extract components}

Under the given chromatographic conditions, a total of 12 different components could be separated from all 48 extracts (peaks A-L in Fig. 1). All components have already been familiar to us from previous studies (e.g., Raspotnig et al. 2008), and were tentatively identified by their EI-mass spectra (peak A: neral; peak B: geranial; peak C: tridecene; peak D: tridecane; peak E: epi-chrysomelidial $=(3 \mathrm{~S}, 8 \mathrm{R})$-chrysomelidial; peak $\mathrm{F}$ : chrysomelidial $=(3 \mathrm{~S}, 8 \mathrm{~S})$-chrysomelidial; peak $\mathrm{G}$ : pentadecene; peak $\mathrm{H}$ : pentadecane; peak I: 6,9-heptadecadiene; peak J: 8-heptadecene; peak K: $\beta$-springene; peak L: octadecadienal). In most cases, a final identification by comparison of retention times to authentic samples was possible (see Table 2), particularly true for neral, geranial, both chrysomelidials and the saturated hydrocarbons (tri- and pentadecane). The position of double bonds in unsaturated hydrocarbons was only determined for the major hydrocarbon compound, a doubly-unsaturated $\mathrm{C}_{17}$-hydrocarbon, namely 6,9-heptadecadiene (peak I). Due to low quantities, double bond positions could not be specified for the tri- and pentadecene (peaks $\mathrm{C}$ and $\mathrm{G}$ ). The $\mathrm{C}_{17: 1}$-hydrocarbon (peak $\mathrm{J}$ ) appeared to be 8-heptadecene, based on mass spectral characteristics and on the comparison of retention times and to an extract of Platynothrus peltifer, another oribatid mite which is known to contain the authentic compound (Raspotnig et al. 2005b). Peaks K and L were tentatively identified as $\beta$-springene and octadecadienal, respectively, based on mass spectral comparison only. However, at least the identification of $\beta$-springene is strongly supported by mass spectral comparisons to spectra from the NIST-library and from literature (Burger et al. 1978; Waterhouse et al. 1996; Schulz et al. 2003; Howard et al. 2003; Bertsch et al. 2004; CruzLopez et al. 2005). Components E and F, epi-chrysomelidial and chrysomelidial, appeared to be poorly separable under the given chromatographic conditions and eluted closely together (RT of peak $\mathrm{E}=13.32 \mathrm{~min}$; RT of peak $\mathrm{F}=13.36 \mathrm{~min}$ ). Thus, in each of the extracts, their identity was additionally checked by a close look at the relation of fragment ions at $\mathrm{m} / \mathrm{z} 148$ and m/z 138 in the EI mass spectra. In chrysomelidial, the intensity of the fragment at $\mathrm{m} / \mathrm{z} 148$ characteristically exceeds the ion at $\mathrm{m} / \mathrm{z} 138$; in epi-chrysomelidial, the opposite is the case (see Raspotnig et al. 2008). A short overview on all analytical data along with some diagnostic mass spectrometric characters is given in Table 2.

\section{Distinct secretion profiles}

The components in the extracts were arranged in four distinct patterns or profiles, each profile corresponding to one of the four Oribotritia-species (Figs. 1, 2). A few parameters were found to be diagnostic or distinguishing characters, even at first sight: (1) The presence or absence of monoterpenes neral and geranial. These compounds were exclusively present in extracts of $O$. banksi but were missing in the three Austrian species. (2) The relation of epi-chrysomelidial/chrysomelidial. Oribotritia banksi showed almost pure epi-chrysomelidial, with only small amounts of chrysomelidial in some samples. By 


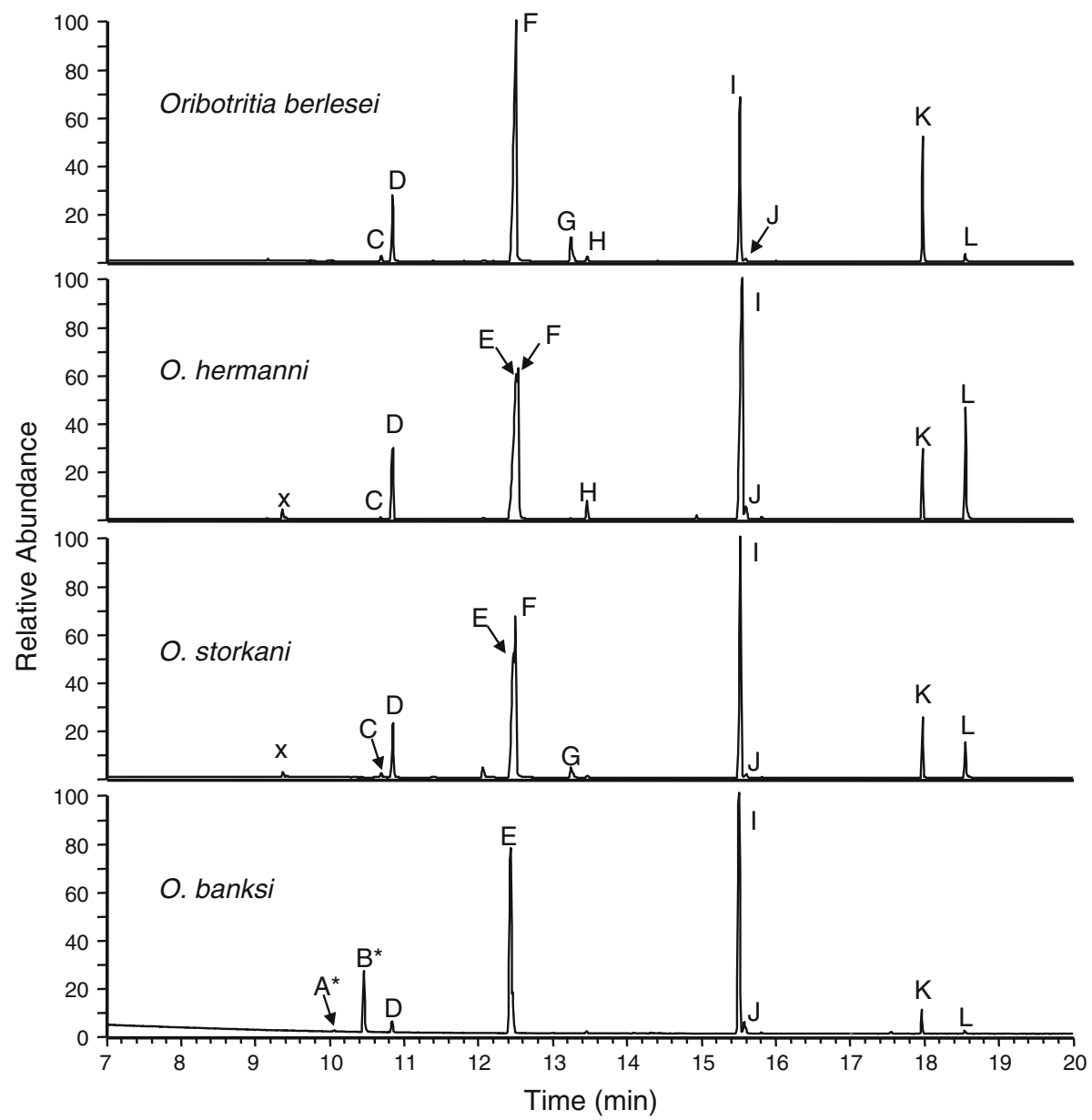

Fig. 1 Typical chromatographic profiles of oil gland secretion from individual extracts of different Oribotritia species. Peak A (neral)*, peak B (geranial)*, peak $C$ (tridecene), peak D (tridecane), peak E (epichrysomeldial), peak $F$ (chrysomelidial), peak $G$ (pentadecene), peak $H$ (pentadecane), peak I (6,9heptadecadiene), peak $J$ (8-heptadecene), peak $K$ ( $\beta$-springene), peak $L$ (octadecadienal). Astigmatid compounds are marked with an asterisk. Double bond positions in tridecene (component $\mathrm{C}$ ) and pentadecene (component G) were not identified; component L (octadecadienal) was only tentatively identified based on a structural proposal from the NIST library. Peaks " $x$ " mark a cluster of small monoterpenes (all with $\mathrm{M}=136$ ) which inconsistently were found in some of the extracts

contrast, in extracts of $O$. berlesei almost pure chrysomelidial, i.e. without or with only small amounts of epi-chrysomelidial, was detected. Oribotritia hermanni and O. storkani were in between, each exhibiting a specific mixture of both chrysomelidials. In detail, in $O$. hermanni the epi-chrysomelidial/chrysomelidial-relation was slightly higher (about 5:4) than in O. storkani (about 1:1). (3) The relation of pentadecene/pentadecane. Oribotritia berlesei constantly showed much more pentadecene than pentadecane (relation about 4:1). A similar situation was demonstrated for O. storkani (relation $\mathrm{C}_{15: 1}: \mathrm{C}_{15}=5: 1$ ). In $O$. hermanni, consistently more pentadecane than pentadecene was detected (relation $\left.\mathrm{C}_{15: 1}: \mathrm{C}_{15}=1: 10\right) . \mathrm{C}_{15}$-hydrocarbons were present but not prominent in the secretion 
Table 2 Gas chromatographic and mass spectral data to components for extracts of Oribotritia-species

\begin{tabular}{|c|c|c|c|}
\hline $\begin{array}{l}\text { Peak } \\
\text { no. }\end{array}$ & $\begin{array}{l}\text { Retention } \\
\text { time (min) }\end{array}$ & Diagnostic characters (mainly from EI-mass spectra) & Identified as \\
\hline A & 10.92 & $\mathrm{M}^{+}$at $\mathrm{m} / \mathrm{z} 152$, further diagnostic ions at $\mathrm{m} / \mathrm{z} 69, \mathrm{~m} / \mathrm{z} 41$ & Neral \\
\hline B & 11.32 & $\mathrm{M}^{+}$at $\mathrm{m} / \mathrm{z} 152$, further diagnostic ions at $\mathrm{m} / \mathrm{z} 69, \mathrm{~m} / \mathrm{z} 41$ & Geranial \\
\hline $\mathrm{C}$ & 11.54 & $\mathrm{M}^{+}$at $\mathrm{m} / \mathrm{z} 182$, series of $\mathrm{C}_{\mathrm{n}} \mathrm{H}_{2 \mathrm{n}-1}$-ions & Tridecene $^{\mathrm{a}}$ \\
\hline $\mathrm{D}$ & 11.69 & $\mathrm{M}^{+}$at $\mathrm{m} / \mathrm{z} 184$, series of $\mathrm{C}_{\mathrm{n}} \mathrm{H}_{2 \mathrm{n}+1}$-ions & Tridecane \\
\hline $\mathrm{E}$ & 13.32 & $\begin{array}{l}\mathrm{M}^{+} \text {at } \mathrm{m} / \mathrm{z} 166(1), 148(7), 138(14), 133(2), 123(10), 119 \\
\quad(4), 109(40), 108(46), 105(15), 95(15), 93(11), 91(20), \\
\quad 81(100), 79(69), 77(31)\end{array}$ & $\begin{array}{l}\text { Epi-chrysomelidial } \\
(=3 \mathrm{~S}, 8 \mathrm{R}- \\
\text { chrysomelidial })\end{array}$ \\
\hline $\mathrm{F}$ & 13.36 & $\begin{array}{l}\mathrm{M}^{+} \text {at } \mathrm{m} / \mathrm{z} 166(7), 151(6), 148(46), 138(25), 109(49), \\
\quad 108(40), 105(30), 95(19), 91(27), 81(100), 79(78), 77 \\
\quad(38)\end{array}$ & $\begin{array}{l}\text { Chrysomelidial (=3S,8S- } \\
\text { chrysomelidial) }\end{array}$ \\
\hline G & 14.10 & $\mathrm{M}^{+}$at $\mathrm{m} / \mathrm{z} 210$, series of $\mathrm{C}_{\mathrm{n}} \mathrm{H}_{2 \mathrm{n}-1}$-ions & Pentadecene $^{\mathrm{a}}$ \\
\hline $\mathrm{H}$ & 14.32 & $\mathrm{M}^{+}$at $\mathrm{m} / \mathrm{z} 212$, series of $\mathrm{C}_{\mathrm{n}} \mathrm{H}_{2 \mathrm{n}+1}$-ions & Pentadecane \\
\hline I & 16.36 & $\begin{array}{l}\mathrm{M}^{+} \text {at } \mathrm{m} / \mathrm{z} 236 \text {; diagnostic ions from DMDS-derivatisation: } \\
\mathrm{M}^{+} \text {at } \mathrm{m} / \mathrm{z} 362 \text {, further ions at } \mathrm{m} / \mathrm{z} 231,203,183,159,155 \\
\text { (base peak) and } \mathrm{m} / \mathrm{z} 131\end{array}$ & 6,9-heptadecadiene \\
\hline $\mathrm{J}$ & 16.44 & $\mathrm{M}^{+}$at $\mathrm{m} / \mathrm{z} 238$, series of $\mathrm{C}_{\mathrm{n}} \mathrm{H}_{2 \mathrm{n}-1}$-ions & 8-heptadecene \\
\hline $\mathrm{K}$ & 18.70 & $\begin{array}{l}\mathrm{M}^{+} \text {at } \mathrm{m} / \mathrm{z} 272(4), 257(3), 229(4), 203(5), 187(10), 161 \\
\quad(17), 133(31), 120(15), 119(17), 107(20), 93(50), 81 \\
\quad(37), 69(100), 55(16), 53(17), 41(59)\end{array}$ & $\beta$-springene ${ }^{\mathrm{b}}$ \\
\hline $\mathrm{L}$ & 19.27 & $\begin{array}{l}\mathrm{M}^{+} \text {at } \mathrm{m} / \mathrm{z} 264(11), 235(3), 221(4), 207(4), 165(4), 151 \\
\quad(7), 137(10), 123(10), 109(22), 95(61), 81(61), 79(52), \\
\quad 67(100), 55(38), 54(32), 44(32), 41(69)\end{array}$ & 9,17 -octadecadienal ${ }^{\mathrm{c}}$ \\
\hline
\end{tabular}

\footnotetext{
${ }^{\mathrm{a}}$ Double bond position not identified

b Identified on the basis of mass spectral comparison with authentic spectrum

c Tentatively identified on the basis of mass spectral data only (proposal from NIST-library)
}

profile of $O$. banksi. 4) The relation of $\beta$-springene to octadecadienal. Much more $\beta$-springene than octadecadienal (relation about 5:1) was found in both O. berlesei (relation 10:1) and in $O$. banksi. In the latter species, octadecadienal generally appeared to be a minor or even a trace component. By contrast, in $O$. storkani, the amounts of $\beta$-springene were higher than (or equal to) octadecadienal with an average relation of $\beta$-springene: octadecadienal $=2: 1$. In $O$. hermanni, consistently more octadecadienal than $\beta$-springene was present (average relation 1:2).

Generally, within extracts of one and the same species, profiles showed a high degree of stability and low variability regardless of population and collection locality as specified in the statistical tests below. Average profiles and species-specific differences of all four species are summarised in Table 3.

\section{Statistical discrimination of profiles}

For a statistical classification of distinct chemical entities or clusters on the basis of individual profiles, cluster analyses with all 48 profiles were performed. As depicted in Fig. 2, we tested different similarity measures including Euclidean distances and the robust Gower coefficient, applicable to the analysis of various (even mixed) types of data (Gower 1967). Hierarchical clustering using the algorithm of unweighted pair-group method 

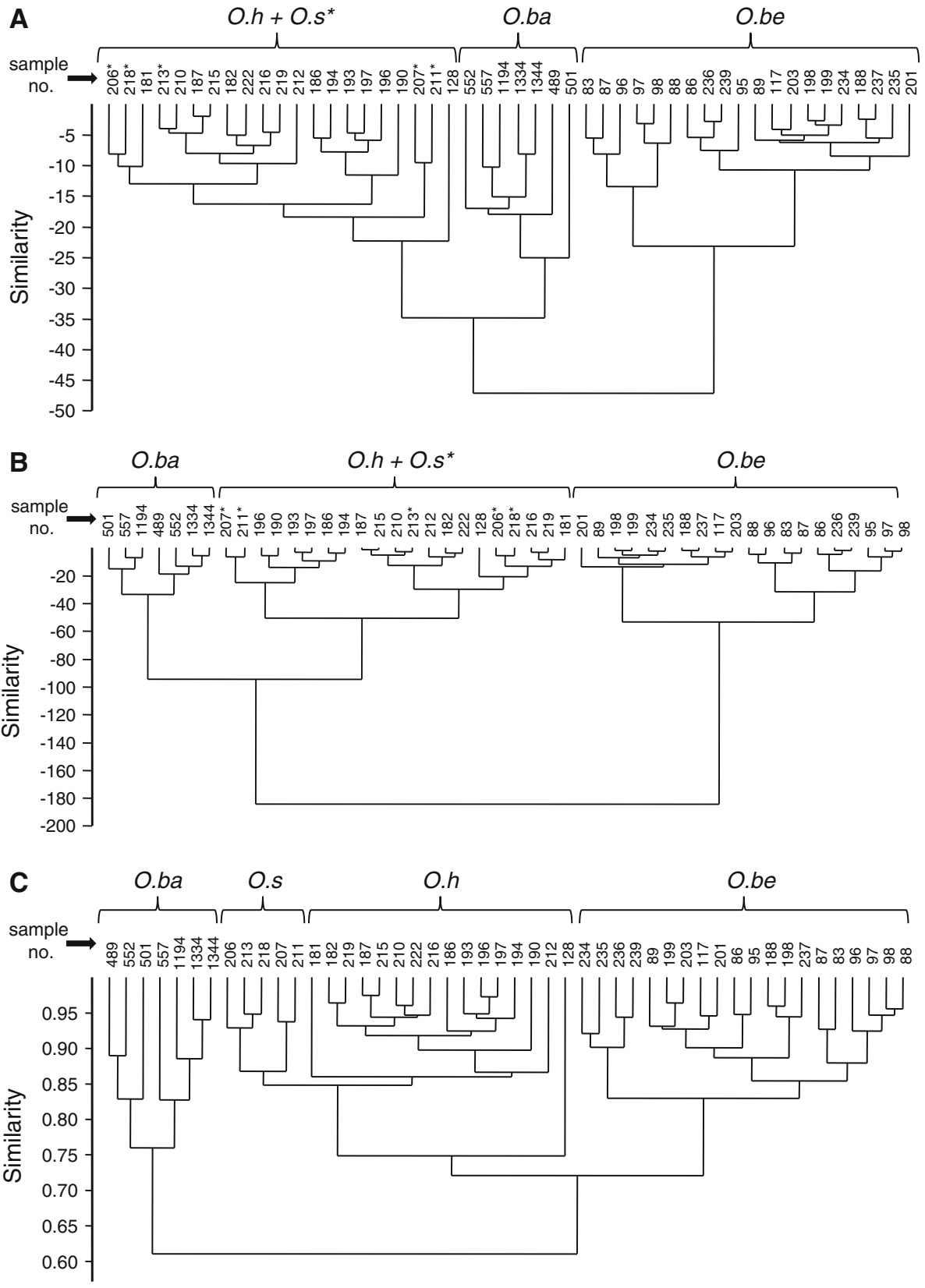

Fig. 2 Cluster analyses based on chemical profiles of individual extracts, using Euclidean distances (a), Ward's method (b) and the Gower coefficient (c). Sample numbers just refer to intern labelling of extracts but also pinpoint the clustering behaviour of samples of different populations within the regarding species (see Table 1). In a and b, extracts of Oribotritia hermanni and O. storkani were not well separable (samples of $O$. storkani are marked with an asterisk). In $\mathbf{a}$ and $\mathbf{b}$, dissimilarity is expressed in $\%$, in $\mathbf{c}$ relative to 1 $(=100 \%$ similarity). See text for further details. Abbreviations: O.ba (Oribotritia banksi), O.be (Oribotritia berlesei), O.h (Oribotritia hermanni), O.s (Oribotritia storkani) 
Table 3 Oil gland secretion profiles in different species of genus Oribotritia

\begin{tabular}{lllll}
\hline Compounds & O. banksi & O. berlesei & O. hermanni & O. storkani \\
\hline A (neral) & $0.1 \pm 0.1$ & 0 & 0 & 0 \\
B (geranial) & $\mathbf{1 4 . 9} \pm \mathbf{5 . 8}$ & 0 & 0 & 0 \\
C $\left(\mathrm{C}_{13: 1}\right)$ & 0 & $0.6 \pm 0.4$ & $0.1 \pm 0.1$ & $0.4 \pm 0.2$ \\
D (C $\left.{ }_{13}\right)$ & $1.6 \pm 1.4$ & $6.3 \pm 1.5$ & $6.0 \pm 1.8$ & $6.9 \pm 1.3$ \\
E (epi-chrysomelidial) & $\mathbf{4 2 . 9} \pm \mathbf{6 . 3}$ & $0.3 \pm 1.3$ & $\mathbf{2 4 . 1} \pm \mathbf{5 . 7}$ & $\mathbf{2 6 . 2} \pm \mathbf{6 . 3}$ \\
F (chrysomelidial) & $2.7 \pm 3.6$ & $\mathbf{4 3 . 8} \pm \mathbf{9 . 3}$ & $\mathbf{1 9 . 3} \pm \mathbf{3 . 7}$ & $\mathbf{2 5 . 2} \pm \mathbf{7 . 4}$ \\
G $\left(\mathrm{C}_{15: 1}\right)$ & $<0.1$ & $3.3 \pm 1.4$ & $0.1 \pm 0.1$ & $1.0 \pm 0.7$ \\
H $\left(\mathrm{C}_{15}\right)$ & $0.4 \pm 0.2$ & $0.8 \pm 0.4$ & $1.0 \pm 0.6$ & $0.2 \pm 0.1$ \\
I (C $\left.\mathrm{C}_{17: 2}\right)$ & $\mathbf{2 7 . 4} \pm \mathbf{8 . 8}$ & $\mathbf{2 5 . 4} \pm \mathbf{4 . 9}$ & $\mathbf{3 6 . 3} \pm \mathbf{7 . 2}$ & $\mathbf{3 1 . 8} \pm \mathbf{5 . 4}$ \\
J (C & $2.6 \pm 1.5$ & $1.0 \pm 0.5$ & $1.1 \pm 0.6$ & $0.3 \pm 0.1$ \\
K ( $\beta$-springene) & $6.0 \pm 4.1$ & $\mathbf{1 6 . 9} \pm \mathbf{6 . 3}$ & $3.9 \pm 1.9$ & $5.2 \pm 2.1$ \\
L (“octadecadienal”) & $1.3 \pm 1.8$ & $1.7 \pm 1.1$ & $8.2 \pm 2.6$ & $2.8 \pm 1.5$ \\
\hline C
\end{tabular}

Components are quantified as \% of whole secretion (based on peak area integration), main components in bold. Profiles are given as mean of $7($ O. banksi), 22 (O. berlesei $), 16(O$. hermanni $)$ and 5 (O. storkani) individuals, respectively

average (UPGMA) and Euclidean distances produced two large clusters, one comprising all specimens of $O$. banksi, $O$. hermanni and $O$. storkani, the second all individuals of $O$. berlesei. Within the first cluster, individuals of $O$. banksi clearly formed one separate sub-cluster while individuals of $O$. hermanni and $O$. storkani clustered together (Fig. 2a). Essentially the same picture was obtained by Ward's method (Fig. 2b). Using the Gower coefficient of similarity, two other clusters could be evaluated, one of these corresponding to $O$. banksi, the second one to all Austrian Oribotritia-species. In this second cluster, individuals of each of the three Austrian species (i.e., O. berlesei, O. hermanni, O. storkani) formed distinctly separated sub-clusters (Fig. 2c) with O. berlesei as a "sistercluster" to O. hermanni plus $O$. storkani. Extract profiles of individuals of the two latter species showed highest similarity though remaining separable.

Irrespective of the method used, the high intra-cluster stability of the chemical profiles (basically corresponding to intraspecific stability) was remarkable. This fact became especially obvious for profiles of $O$. berlese $i$ and to a certain extent also for $O$. hermanni where individuals of several populations were included (Table 1). For the five populations of $O$. berlesei, for instance, profiles of individuals of different populations clustered together and cluster-formation was not clearly correlated with allocation to a specific population (Fig. 2; see also Table 1 for extract numbers and populations). By contrast, clusters clearly corresponding to individuals of one collection were noticed for $O$. banksi.

Only one (of the 48) samples appeared to be generally misplaced-this was one extract profile of $O$. hermanni (internal number pr128) showing the lowest absolute amount of secretion of all extracts, making a quantification of minor but diagnostic components (such as the $\mathrm{C}_{15}$-hydrocarbons) very difficult and possibly inaccurate.

Following cluster analysis, a stepwise discriminant analysis was carried out (again done with all 48 extract profiles), and four distinct chemical groups corresponding to the four species could be verified. Individuals of $O$. hermanni and $O$. storkani formed two closely adjacent groups (Fig. 3) but nevertheless appeared to be chemically completely separated. In statistical terms, $100 \%$ of cases (=individual profiles) were correctly assigned to the four previously defined morphological groups (=species). Function 1 explained $71.6 \%$ of 


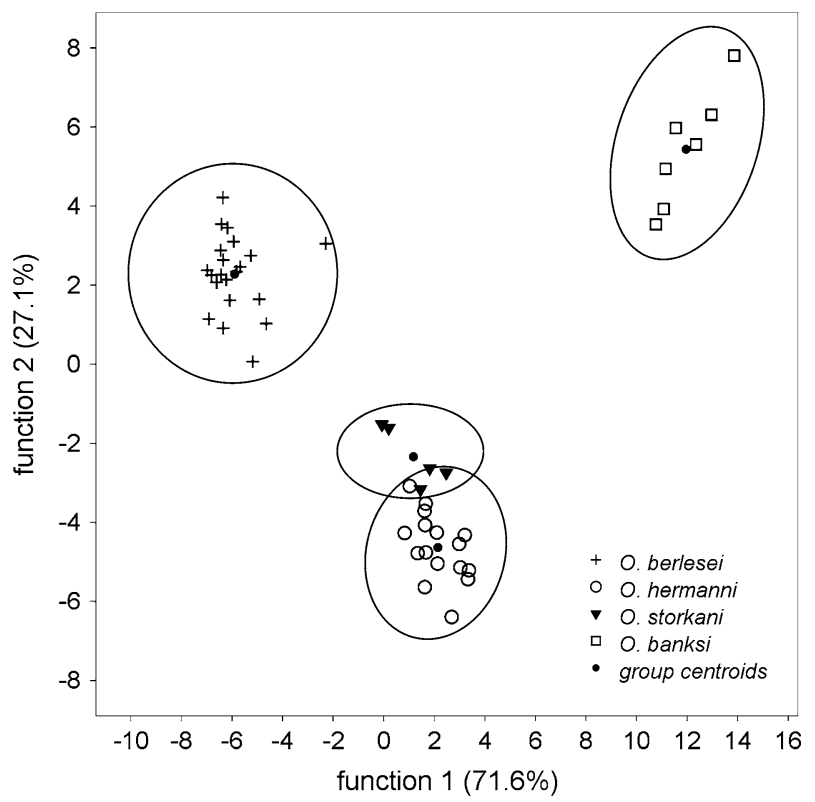

Fig. 3 Canonical discriminant analysis of individual oil gland secretion profiles of 48 individuals of the four Oribotritia species. Four chemical groups were verified, each corresponding to one species (see text for details)

variance (Wilks' Lambda $=0.001, P<0.001$ ), whereas function 2 explained $27.1 \%$ of variance (Wilks' Lambda $=0.036, P<0.001$ ) and function 3 explained only $1.3 \%$ of variance, but remained significant (Wilks' Lambda $=0.579, P<0.001$ ).

\section{Discussion}

Euphthiracaroid oil gland chemistry

As outlined in a series of studies on the oil gland chemistry of Oribatida (e.g., Raspotnig et al. 2001, 2003, 2004, 2005a, b, 2008, 2009; Sakata and Norton 2001, 2003; Sakata et al. $1995 ; 2003)$, we proceed on the assumption that all components found in the extracts originated from extremely large developed oil glands of the oribatid specimens investigated. The present investigation, now done with a wider range of Oribotritia-species from two continents, underlines our previous results on the unusual, iridoid monoterpene-rich oil gland chemistry in Oribotritia berlesei (Raspotnig et al. 2008), strongly indicating that chrysomelidials represent general characteristics of the genus Oribotritia. Preliminary investigations by the authors regarding species of Mesotritia (Oribotritiidae) and Rhysotritia (Euphthiracaridae) support an even wider distribution of chrysomelidials among the Euphthiracaroidea even though these compounds were not detected in e.g., Microtritia and Euphthiracarus (both Euphthiracaridae). On the other hand, chrysomelidials appear to be missing in any other group of oil gland-bearing Oribatida outside the Euphthiracaroidea and are obviously also extremely rare in other animals: To our knowledge, these 
compounds have only been reported from exocrine glands of certain Coleoptera, mainly from larval secretions of some chrysomelid beetles (Blum et al. 1978; Pasteels et al. 1982, 1984, 1988; Sugawara et al. 1979a, b; Weibel et al. 2001).

According to the few phylogenetic studies on Euphthiracaroidea, the Oribotritiidae may be considered basal within this superfamily (e.g., Haumann 1991) or within one of its subclades (e.g., Mahunka 1990). Thus, chrysomelidials (most probably as a mixture of both stereoisomers) might have evolved very early in ancestral euphthiracaroids. Since both American and Austrian Oribotritia-species showed oil gland secretion profiles containing chrysomelidials (sharing also other compounds such as $\beta$-springene), this characteristic secretion chemistry is possibly more than 65 million years old (=time of continental separation) and obviously exhibits a high degree of conservatism. On the other hand, the presence of one single stereoisomer of chrysomelidial in the secretions of certain species (e.g., nearly pure epi-chrysomelidial in $O$. banksi or nearly pure chrysomelidial in $O$. berlesei) may be regarded as a derivative feature. No detailed studies on the oil gland chemistry of representatives of other Euphthiracaroidea are so far available, but preliminary chemical results from genera Rhysotritia, Mesotritia, Microtritia, and Euphthiracarus (unpublished data) consistently indicate that euphthiracaroids in general represent a group chemically distinct from other mixonomatans. This situation becomes especially obvious when comparing oil gland secretion profiles of Oribotritia spp. to probably closely related (but mainly Astigmata compounds-bearing) Collohmannia gigantea (Grandjean 1969; Raspotnig 2006b; Raspotnig et al. 2001).

\section{“Astigmata compounds"}

Euphthiracaroids are usually treated as a part of the oribatid cohort Mixonomata (Grandjean 1969; Weigmann 2006) many of which are known to produce "Astigmata compounds" in their opisthonotal glands (e.g., Raspotnig 2010). With the monophyletic origin of these compounds assumed, their occurrence is a strong argument for the evolutionary origin of Astigmata within ancient Astigmata compounds-bearing Oribatida (Norton 1998; Sakata and Norton 2001). This view has meanwhile also found its way into current textbooks of Acarology (Krantz et al. 2009). Due to the generally accepted phyletic status of oribotritiids within Mixonomata, Astigmata compounds were also to be expected in this group. Surprisingly, Raspotnig et al. (2008) could not find any sign of Astigmata compounds in the oil gland secretion of $O$. berlesei. The results presented now may clarify this situation: Oribotritia, and thus all Euphthiracaroidea, clearly belong to the group of Astigmata compounds-bearing Oribatida, as indicated by remnants of Astigmata compounds neral and geranial in the oil glands of American $O$. banksi. Following this view, the lack of Astigmata compounds in the three Austrian species of Oribotritia is considered to be due to their complete reduction. A situation like this is not unusual for oil glands of Oribatida. Though Astigmata compounds are produced in many mixonomatans, in many desmonomatans and in Astigmata, these compounds have been subjected to major evolutionary changes in other (more derivative) groups. In many brachypylines, for instance, Astigmata compounds appear to be reduced and replaced by other components (for instance by alkaloids) but are still detectable in juveniles, indicating the ancestral state (e.g., Takada et al. 2005). In oribotritiids, and most likely in all Euphthiracaroidea, a similar evolutionary trend may have led to the reduction of Astigmata compounds and to their replacement by other components (in this case, iridoid monoterpenes). Similar glandmodifying trends in glandulate Oribatida obviously took place several times independently, sometimes even leading to regressive loss of oil glands, as assumed for Phthiracaroidea, 
Malaconothridae and for certain Camisiidae. In the latter family, a regressive trendresulting in small and functionless oil glands-could even be traced across certain genera and species (Raspotnig et al. 2009).

Species-specific oil gland secretion profiles and the detection of cryptic species

One important result of the study is the further establishment of oil gland secretion profiles as specific and discriminant characters for chemosystematic studies in Oribatida. Oil gland secretion profiles, not only those of Oribotritia, appear to be generally species-specific, even allowing the discrimination of closely related, syntopically occurring species of one genus. For instance, a chemical study with species of the Trhypochthonius-species-complex (Oribatida, Desmonomata) led to the detection of several phyletic lineages within this group, being clearly distinguishable by their oil gland secretion profiles (Heethoff et al. 2011). In this case, subsequent morphological and molecular investigations resulted in the description of new forms and subspecies in the T. tectorum-species complex (Weigmann and Raspotnig 2009).

Oil gland secretion profiles obviously not only represent an important tool in studies of oribatid gross systematics (Raspotnig 2006a, 2010) but are also important for lower-level taxonomy such as for the discrimination of morphologically very similar or even cryptic species. With respect to Oribotritia, only one species was so far reported for Austria: According to Schatz (1983) this was "Oribotritia decumana" which was found to be a nomen nudum and a synonym of $O$. berlesei. In the course of our chemical investigations on oil gland profiles of $O$. berlesei, we detected clearly deviating oil gland secretion profiles that indicated the presence of three distinct chemical groups. This situation led us to a more rigorous morphological examination of the specimens of our collections and finally resulted in the discovery of $O$. hermanni and $O$. storkani in addition to $O$. berlesei, with the two former species not previously recorded for Austria. We further recognised other profiles in Oribotritia-specimens of our collections-again chemically distinct from the four profiles herein described. Preliminary morphological investigations indicate that specimens showing these aberrant profiles do not belong to any of three Austrian species mentioned above. For Europe, only a few species of Oribotritia have been described: Apart from $O$. berlesei, O. hermanni, and $O$. storkani, O. fennica has been reported from Northern Europe (Märkel 1964), O. serrata from Romania (Feider and Suciu 1958) and O. hauseri from Greece (Mahunka 1982). However, our findings might indicate a much larger number of still undescribed Oribotritia-species in Austria and surrounding regions.

Acknowledgments This work was supported by the Austrian Science Fund (FWF), project numbers P18486 and P21819. We further thank Prof. Dr. Roy A. Norton (SUNY ESF, Syracuse, New York) for providing soil samples containing Oribotritia banksi.

Open Access This article is distributed under the terms of the Creative Commons Attribution Noncommercial License which permits any noncommercial use, distribution, and reproduction in any medium, provided the original author(s) and source are credited.

\section{References}

Bellesia F, Guelfi F, Pagnoni UM, Pinetti A (1986) The base-catalyzed cyclization of 10-oxocitral. Synthesis of chrysomelidial and dehydroiridodial. Tetrahedron Lett 27:381-382 
Bertsch A, Schweer H, Titze A (2004) Analysis of the labial gland secretions of the male bumblebee Bombus griseocollis (Hymenoptera: Apidae). Z Naturforsch 59C:701-707

Blum MS, Wallace JB, Duffield RM, Brand JM, Fales HM, Sokoloski EA (1978) Chrysomelidial in the defensive secretion of the leaf beetle Gastrophysa cyanea Melsheimer. J Chem Ecol 4:47-53

Burger BV, Le Roux M, Spies HSC, Truter V, Bigalke RC (1978) Mammalian pheromone studies. III. (E, E)-7, 11, 15-Trimethyl-3-methylenehexadeca-1, 6, 10, 14-tetraene, a new diterpene analogue of $\beta$-farnesene from the dorsal gland of the springbok, Antidorcas marsupialis. Tetrahedron Lett 52: 5221-5224

Cruz-Lopez L, Malo EA, Morgan ED, Rincon M, Guzman M, Rojas JC (2005) Mandibular gland secretion of Melipona beecheii: chemistry and behavior. J Chem Ecol 31:1621-1632

Feider Z, Suciu I (1957) Contribution a la connaissance des Oribates (Acariens) de la R.P.R.-Familia Phthiracaridae Perty 1841. Acad Stud Biol Agric 8:23-48

Feider Z, Suciu I (1958) O noua contributie la cunoasterea Oribatidelor (Acari) din R.P. R. Stud Cercet Biol, ser Biol anim 1(10):31-44

Forsslund KH, Märkel K (1963) Drei neue Arten der Fam. Euphthiracaridae (Acari, Oribatei). Entomol Ts Arg 84:284-296

Gower JC (1967) A comparison of some methods of cluster analysis. Biometrics 23:623-637

Grandjean F (1933) Structure de la region ventral chez quelques Ptyctima (Oribates). Bull Mus 2e serie 5:309-315

Grandjean F (1934) Les poils des epimeres chez les oribates (Acariens). Bull Mus nat Hist natur 2(6):504-512

Grandjean F (1954) Essai de classification des Oribates (Acariens). Bull Soc Zool Fr 78:421-446

Grandjean F (1967) Nouvelles observations sur les Acariens ( $5^{\mathrm{e}}$ serie). Acarologia 9:242-272

Grandjean F (1969) Considerations sur le classement des Oribates. Leur division en 6 groupes majeurs. I. Les affinites de Collohmannia gigantea Sellnick, 1922. Acarologia 11:127-153

Haumann G (1991) Zur Phylogenie primitiver Oribatiden (Acari: Oribatida). dbv-Verlag, Graz, p 237

Heethoff M, Laumann M, Weigmann G, Raspotnig G (2011) Integrative taxonomy: combining morphological, molecular and chemical data for species delineation in the parthenogenetic Trhypochthonius tectorum complex (Acari, Oribatida, Trhypochthoniidae). Front Zool 8:2

Howard RW, Baker JE, Morgan ED (2003) Novel diterpenoids and hydrocarbons in the Dufour gland of the ectoparasitoid Habrobracon hebetor (Say) (Hymenoptera: Braconidae). Arch Insect Biochem Physiol 54:95-109

Krantz GW, Walter DE (eds) (2009) A manual of acarology, 3rd edn. Texas Tech University Press, Lubbock, p 807

Mahunka S (1982) Neue und interessante Milben aus dem Genfer Museum XXXIX. Fifth contribution to the oribatid fauna of Greece (Acari: Oribatida). Rev Suisse Zool 89:497-515

Mahunka S (1990) A survey of the superfamily Euphthiracaroidea Jacot, 1930 (Acari: Oribatida). Folia Entomol Hung 51:37-80

Märkel K (1964) Die Euphthiracaridae Jacot, 1930, und ihre Gattungen (Acari, Oribatei). Zoologische Verhandelingen 67:3-78

Niedbala W (2002) Ptyctimous mites (Acari, Oribatida) oft he Nearctic region. Monogr up siles Mus 4:1-261

Norton RA (1998) Morphological evidence for the evolutionary origin of Astigmata. Exp Appl Acarol 22:559-594

Pasteels JM, Breakman J-C, Daloze D, Ottinger R (1982) Chemical defence in chrysomelid larvae and adults. Tetrahedron 38:1891-1897

Pasteels JM, Rowell-Rahier M, Breakman J-C, Daloze D (1984) Chemical defences in leaf beetles and their larvae: the ecological, evolutionary and taxonomic significance. Biochem Syst Ecol 12:395-406

Pasteels JM, Breakman J-C, Daloze D (1988) Chemical defense in the Chrysomelinae. In: Jolivet P, Petitpierre E, Hsiao TH (eds) Biology of Chrysomelidae. Kluwer, Dordrecht, pp 233-252

Raspotnig G (2006a) Characterisation of monophyletic oribatid groups by oil gland chemistry-a novel systematic approach in Oribatida (Acari). Abh Ber Naturkundemus Görlitz 78:31-46

Raspotnig G (2006b) Chemical alarm and defence in the oribatid mite Collohmannia gigantea (Acari: Oribatida). Exp Appl Acarol 39:177-194

Raspotnig G (2010) Oil gland secretions in Oribatida (Acari). In: Sabelis MW, Bruin J (eds) Trends in Acarology (Proc 12th Int Congr Acarol). Springer, Netherlands, pp 235-239

Raspotnig G, Föttinger P (2008) Analysis of individual oil gland secretion profiles in oribatid mites (Acari: Oribatida). Int J Acarol 34:409-417

Raspotnig G, Schuster R, Krisper G, Fauler G, Leis HJ (2001) Chemistry of the oil gland secretion of Collohmannia gigantea (Acari: Oribatida). Exp Appl Acarol 25:933-946 
Raspotnig G, Schuster R, Krisper G (2003) Functional anatomy of oil glands in Collohmannia gigantea (Acari, Oribatida). Zoomorphology 122:105-112

Raspotnig G, Krisper G, Schuster R (2004) Oil gland chemistry of Trhypochthonius tectorum (Acari: Oribatida) with reference to the phylogenetic significance of secretion profiles in the Trhypochthoniidae. Int J Acarol 30:369-374

Raspotnig G, Krisper G, Schuster R (2005a) Ontogenetic changes in the chemistry and morphology of oil glands in Hermannia convexa (Acari: Oribatida). Exp Appl Acarol 35:47-58

Raspotnig G, Krisper G, Schuster R, Fauler G, Leis HJ (2005b) Volatile exudates from the oribatid mite, Platynothrus peltifer. J Chem Ecol 31:419-430

Raspotnig G, Kaiser R, Stabentheiner E, Leis HJ (2008) Chrysomelidial in the opisthonotal glands of the oribatid mite, Oribotritia berlesei. J Chem Ecol 34:1081-1088

Raspotnig G, Stabentheiner E, Föttinger P, Schaider M, Krisper G, Rechberger G, Leis HJ (2009) Opisthonotal glands in the Camisiidae (Acari, Oribatida): evidence for a regressive evolutionary trend. J Zool Syst Evol Res 47:77-87

Raspotnig G, Norton RA, Heethoff M (2011) Oribatid mites and skin alkaloids in poison frogs. Biol Lett. doi:10.1098/rsbl.2010.1113

Sakata T, Norton RA (2001) Opisthonotal gland chemistry of early-derivative oribatid mites (Acari) and its relevance to systematic relationships of Astigmata. Int J Acarol 27:281-291

Sakata T, Norton RA (2003) Opisthonotal gland chemistry of a middle-derivative oribatid mite, Archegozetes longisetosus (Acari: Trhypochthoniidae). Int J Acarol 29:345-350

Sakata T, Tagami K, Kuwahara Y (1995) Chemical ecology of oribatid mites. I. Oil gland components of Hydronothrus crispus Aoki. J Acarol Soc Jpn 4:69-75

Sakata T, Shimano S, Kuwahara Y (2003) Chemical ecology of oribatid mites. III. Chemical composition of oil gland exudates from Trhypochthoniellus sp. and Trhypochthonius japonicus (Acari: Trhypochthoniidae). Exp Appl Acarol 29:279-291

Saporito R, Donelly MA, Norton RA, Garaffo HM, Spande TF, Daly JW (2007) Oribatid mites as a major source for alkaloids in poison frogs. PNAS 104:8885-8890

Schatz H (1983) Catalogus faunae Austriae. Teil IXi. U.-Ordn.: Oribatei, Hornmilben. Verlag der Österreichischen Akademie der Wissenschaften, Wien, p 118

Schulz S, Krückert K, Weldon PJ (2003) New terpene hydrocarbons from the Alligatoridae (Crocodylia, Reptilia). J Nat Prod 66:34-38

Sugawara F, Matsuda K, Kobayashi A, Yamashita K (1979a) Defensive secretion of chrysomelid larvae Gastrophysa atrocyanea Motschulsky and Phaedon brassicae Baly. J Chem Ecol 5:635-641

Sugawara F, Matsuda K, Kobayashi A, Yamashita K (1979b) Defensive secretion of chrysomelid larvae Linaeidea aenea Linne and Plagiodera versicolora distincta Baly. J Chem Ecol 5:929-934

Takada W, Sakata T, Shimano S, Enami Y, Mori N, Nishida R, Kuwahara Y (2005) Scheloribatid mites as the source of pumiliotoxins in dendrobatid frogs. J Chem Ecol 31:2403-2415

Vincenti M, Guglielmetti G, Cassani G, Tonini C (1987) Determination of double bond position in diunsaturated compounds by mass spectrometry of dimethyl disulfide derivatives. Anal Chem 59:694-699

Waterhouse JS, Ke J, Pickett JA, Weldon PJ (1996) Volatile components in the dorsal gland secretion of the collared peccary, Tayassu tajacu (Tayassuidae, Mammalia). J Chem Ecol 22:1307-1314

Weibel DB, Oldham NJ, Feld B, Glombitza G, Dettner K, Boland W (2001) Iridoid biosynthesis in staphylinid rove beetles (Coleoptera: Staphylinidae, Philonthinae). Insect Biochem Mol Biol 31:583-591

Weigmann G (2006) Hornmilben (Oribatida). Die Tierwelt Deutschlands, 76. Teil. Goecke \& Evers, Keltern

Weigmann G, Raspotnig G (2009) Comparative morphological and biometrical studies on Trhypochthonius species of the tectorum species group (Acari: Oribatida: Trhypochthoniidae). Zootaxa 2269:1-31 